\title{
Outcome of Early vs. Delayed Invasive Intervention in Acute Coronary Syndrome Patients Attending a Selected Specialized Hospital: A Comparative Study
}

\author{
Masuma Jannat Shafi, Sahela Nasrin \\ Ibrahim Cardiac Hospital \& Research Institute, Bangladesh
}

Key Words:
Acute Coronary
Syndrome,
Percutaneous
Coronary
Intervention,
outcome after
revascularization.

\begin{abstract}
:
Background: This study was to compare the outcome of early versus delayed invasive intervention in acute coronary syndrome (ACS) patients.

Methods: A total of 200 patients with ACS underwent early intervention group $(d " 24 h, n=100)$ and delayed intervention group ( $>24$ to $72 h, n=100)$ after percutaneous coronary intervention (PCI) were enrolled. The probable outcomes were a composite of re-infarction, acute LVF, recurrent ischemia, repeat revascularization, bleeding, stroke or death at 30 days.

Results: Male were predominating (74\%vs26\%). Left anterior descending artery was the commonest infarct related artery in both groups $(p=0.114)$. Cardiac markers, Cardiogenic shock, Acute left ventricular failure $(L V F)$ and ventilator requirement were significantly higher $(p=0.007, p=0.060, p=0.009, p=0.002)$ and mean duration of hospital stay was longer $(p<0.001)$ in delayed intervention group. At 30 days follow-up improvement of chest pain, LVF and ejection fraction were achieved significantly in patient undergoing early intervention ( $p<0.001, p=0.016,54.7 \pm 7.4$ vs. 48.4 $6.9 ; p<0.001)$. Adverse outcome like acute $L V F$ ( $7 \%$ vs. $21 \% ; p=0.004)$, re-infarction ( $0 \%$ vs. $7 \% ; p=0.007)$, acute kidney injury (AKI) $(5 \%$ vs. $17 \% ; p=0.007)$, bleeding (11\% vs. $18 \%$; $p=0.160)$, stroke (3\% vs. $9 \%$; $p=0.074)$, repeat revascularization $(1 \%$ vs. $7 \%$; $p=0.032)$, death $(0 \%$ vs. $5 \% ; p=0.030)$ was higher in delayed invasive intervention group $(p=0.001)$.

Conclusion: Acute LVF, ventilator requirement and duration of hospital stay were significantly predominating in delayed intervention group. Early invasive strategy in ACS patient associated with lower rates of acute LVF, acute kidney injury, re-infarction, stroke, bleeding, repeat revascularization and death compared with delayed invasive strategy at 30 days of follow-up.
\end{abstract}

(Cardiovasc. j. 2019; 11(2): 129-138)

\section{Introduction:}

Acute coronary syndrome(ACS) is a major cause of mortality in developing countries and are responsible for a large number of hospitalization annually. ${ }^{1}$ In between $9 \%$ to $19 \%$ of patients with ACS die in the first 6 months after being diagnosed, with about one-half of deaths occurring within 30 days of diagnosis. ${ }^{2}$ ACS encompasses acute ST segment elevation myocardial infarction (STEMI) and non-ST segment elevation acute coronary syndrome (NSTE-ACS) \& UA (unstable angina).

Effective and timely reperfusion of the infarct related coronary artery is central to optimal treatment for both STEMI and NSTE-ACS and efficiently achieved by percutaneous coronary intervention (PCI). ${ }^{3}$ STEMI represents the most lethal types of ACS, one in which a completely occlusive thrombus causes in total cessation of coronary blood flow in the territory of the occluded artery \& the resultant ST-segment elevation on the ECG. If the door to balloon (D2B) time can be maintain within 90 minutes of a STEMI the choice of reperfusion should be Primary Percutaneous Coronary Intervention (PPCI). Recent studies have continued to demonstrate clear superiority of primary PCI over pharmacologic reperfusion, improved event-

Address of Correspondence: Dr. Masuma Jannat Shafi, Department of Cardiology, Ibrahim Cardiac Hospital \& Research Institute, Dhaka, Bangladesh. Email-dr.masumashafi@gmail.com

(C) 2018 authors; licensed and published by International Society of Cardiovascular Ultrasound, Bangladesh Chapter and Bangladesh Society of Geriatric Cardiology. This is an Open Access article distributed under the terms of the CC BY NC 4.0 (https:// creativecommons.org/licenses/by-nc/4.0). 
free survival and lower incidence of intracranial bleeds even for patients who need to be transferred to a tertiary center. ${ }^{4}$ In our country this is not always possible due to financial constrain and lack of knowledge about the outcome of the procedure. Beside this misbelieve about the procedure also plays a role.

Furthermore, rescue PCI and early routine postthrombolysis angiography with subsequent PCI have shown to reduce the rates of re-infarction and recurrent ischemia in comparison to a conservative strategy. ${ }^{5}$

NSTE-ACS are a more frequent clinical presentation than STEMI and are associated with a poorer long-term prognosis. ${ }^{6,7}$ Among NSTE-ACS patient a routine strategy of early angiography and revascularization (PCI) in both sexes improve clinical outcome and lowers rates of recurrent ischemia, re-hospitalization, repeat revascularization, myocardial infarction(MI) and reduced rate of death in comparison with a conservative strategy. ${ }^{8-10}$ It has been additionally become apparent that an early invasive approach is also beneficial in patients with UA. UA is unusually secondary to reduce myocardial perfusion usually from coronary artery atherothrombosis. ISARCOOL trial was recently attributable to lower rates of new $\mathrm{MI}$ in patients with immediate intervention. ${ }^{11}$ Data for the CARESS in AMI study recently reported that high risk patient presenting withevolving STEMI who undergo thrombolytic therapy should be transferred for PCI early after thrombolysis regarding of the success of thrombolytic therapy. ${ }^{12}$

So this study indicate that an early as opposed to a delayed invasive strategy is safe and associated with a lower risk of refractory ischemia and a shorter duration of hospital stay.

\section{Methods:}

Descriptive cross sectional study by systematic sampling technique was conducted in all adult patients presented with acute coronary syndrome and underwent PCI during hospitalization at the Department of Cardiology in Ibrahim Cardiac Hospital \& Research Institute, Dhaka, Bangladesh during the period from January to June 2017.
A total of 200 patients with Acute Coronary Syndrome underwent early intervention group (d"24 h, n=100) and delayed intervention group ( $>24$ to $72 \mathrm{~h}, \mathrm{n}=100$ ) after PCI were enrolled.Thrombolytic patients underwent PCI according to their arrival time up to 72 hours. The patient who received thrombolysis was included after 2 hours of thrombolysis either in early or delayed intervention group.Those who arrived within 24 hours of thrombolysis were included in early intervention group.

Brief history, clinical parameters, demographic characteristics, risk factors, ECG, LV ejection fraction, lab investigations, angiographic \& procedural data, in hospital outcome \& after 30 days follow-up outcome of PCI were analyzed.

Patients with STEMI undergone primary PCI within door to balloon (D2B) time of 90 minutes were excluded. STEMI patients, who underwent PCI beyond 90 minutes but within 24 hours, were considered as early invasive group.

Also patient with prior myocardial infarction, previous history of revascularization (PCI or CABG surgery), mechanical complication of MI, cardiogenic shock, valvular or congenital heart disease and cardiomyopathy. Serum creatinine level $>2 \mathrm{mg} / \mathrm{dl}$, patient with thrombocytopenia, bleeding disorder, advanced malignancy, chronic liver disease, severe anaemia and patient who did not give consent for coronary angiography were excluded.

Verbal informed written consent was taken from patients prior to enrollment. Ethical approval was obtained from the ethical review committee ofIbrahim Cardiac Hospital \& Research Institute.

Outcome variables in hospital after PCI were death (related to the procedure), MI related to PCI, cardiogenic shock, acute heart failure, cerebral stroke, bleeding and re-infarction.

Follow-up comprised into two parts during hospital stay and 30 days after PCI includes: Repeat hospitalization, recurrent ischemia, MI, heart failure, death, bleeding, stroke and repeat revascularization.

Patients were followed up; up to entire duration of hospital stay until time of discharge. Chest 
pain, shortness of breath, palpitation, bleeding etc. were looked for and documented following PCI.

Clinical parameters, pulse, blood pressure, chest and pre cordial auscultation, peripheral pulses, vascular access sites were examined and any abnormalities were noted. ECG was done daily for the first 24 hours after PCI, where there was ongoing chest pain further blood sample were taken for Troponin-I estimation.

At 30 days patients were followed up further to find out any complication at one month following PCI over telephone and short - term outcome variable were documented.

Statistical analysis was carried out by using SPSS 16.0 (statistical package for the social sciences by SPSS Inc. Chicago,ii, USA, 2007. Continuous variables were expressed as mean values \pm standard deviation and compared using Student's t-test. Categorical variables were expressed as frequencies with corresponding percentage and compared using chi-square test. Multiple logistic regression analysis was performed to identify predictors of short-term adverse outcome. A $p$ value of $<0.5$ was considered statistically significant.

\section{Results:}

A total of 200 ACS patients were selected in this prospective observational study. 100 patients were consecutively assigned to the early intervention group (group-1), who underwent PCI within $24 \mathrm{hrs}$ of presentation and 100 patients to the delayed intervention group (group-2) who underwent PCI after 24 to $72 \mathrm{hrs}$ of presentation. Patient was diagnosed as STEMI, NSTEMI and UA based on clinical assessment, ECG evidence and laboratory evaluation. A complete 30 days follow up was performed in both groups. The main objective of the study was to assess the outcome and observe for any complication including re- infarction, recurrent ischemia, repeat revascularization, bleeding, stroke or death in patients undergoing early and delayed invasive intervention.

Table I shows the demographic characteristics where there are no significant intergroup difference between the age \& sex distribution of the population $(p=0.722$ and $p=0.622)$.

\section{Table-I}

Comparison of patients by their demographic characteristics $(N=200)$.

\begin{tabular}{lccc}
$\begin{array}{l}\text { Demographic } \\
\text { characteristics }\end{array}$ & $\begin{array}{c}\text { Early } \\
(\mathrm{n}=100)\end{array}$ & $\begin{array}{c}\text { Group } \\
(\mathrm{n}=100)\end{array}$ & p-value \\
Age $^{*}$ (years) & $55.5 \pm 10.7$ & $54.9 \pm 11.8$ & 0.722 \\
Sex $^{*}$ & & & \\
Male & $74(74.0)$ & $77(77.0)$ & 0.622 \\
Female & $26(26.0)$ & $23(23.0)$ & \\
\hline
\end{tabular}

Figures in the parentheses indicate corresponding \%;

* Chi-square Test was done to analyze the data.

\# Data were analyzed usingUnpaired t-Test and were presented as mean $\pm \mathrm{SD}$.

Figure 1 shows $39 \%$ of the patients in early invasive group and $36 \%$ of the patients in delayed invasive group had normal BMI. Over half of the patients in both groups were overweight or obese (58\% and $63 \%)$.

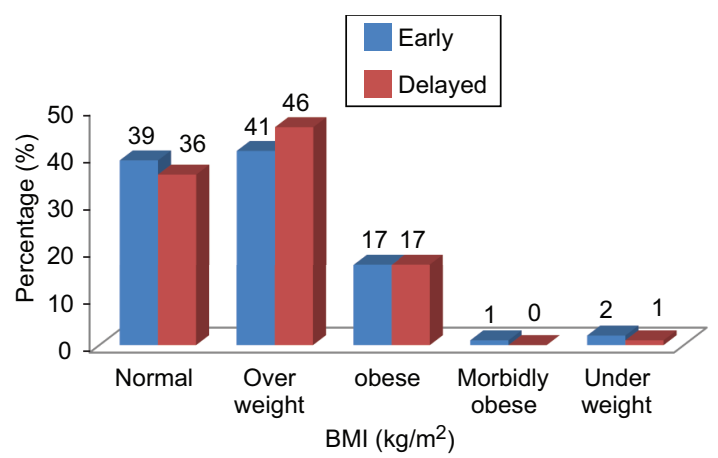

Fig.-1: Comparison of patients by their BMI.

Table II shows there was no significant differences in major risk between groups. In contrast HTN demonstrated their significant presence in the delayed invasive group (64\% vs. $73 \% \mathrm{p}=0.171$ ). Diabetes, dyslipidaemia and family history of CAD prevalence were equal in both groups. There was more CKD patient underwent early intervention $(p=0.014)$ than delayed group.

Table III shows Chest pain, shortness of breath and ventilator requirement was frequently observed ( $p<0.001,0.020$ and 0.002$)$ in delayed intervention group and hospital stay was shorter in the early strategy compared with the delayed $(p<0.001)$ intervention strategy. Cardiogenic shock, ALVF were significantly higher $(\mathrm{p}=0.060$, $\mathrm{p}=0.009)$ in delayed group.

Table IV shows the delayed PCI group was more likely to present with biomarker elevation (95\% vs. $83 \%$ ). S. creatinine, NT pBNP and SGPT 
Table-II

Comparison of patients by their risk factors $(N=200)$.

\begin{tabular}{|c|c|c|c|}
\hline \multirow[t]{2}{*}{ Cardiovascular risk factor } & \multicolumn{2}{|c|}{ Group } & \multirow[t]{2}{*}{ p-value } \\
\hline & Early $(n=100)$ & Delayed $(n=100)$ & \\
\hline \multicolumn{4}{|l|}{ Smoking * } \\
\hline Current & $63(58.0)$ & $65(65.0)$ & 0.486 \\
\hline Former & $11(11.0)$ & $12(12.0)$ & \\
\hline No smoking & $26(26.0)$ & $23(23.0)$ & \\
\hline Alcohol ** & $3(3.0)$ & $1(1.0)$ & 0.311 \\
\hline $\mathrm{HTN}^{*}$ & $64(64.0)$ & $73(73.0)$ & 0.171 \\
\hline $\mathrm{DM}^{*}$ & $59(59.0)$ & $58(58.0)$ & 0.886 \\
\hline $\mathrm{CKD}^{* *}$ & $6(6.0)$ & $0(0.0)$ & 0.014 \\
\hline $\mathrm{DL}^{*}$ & $38(38.0)$ & $33(33.0)$ & 0.460 \\
\hline FH CAD* & $9(9.0)$ & $9(9.0)$ & 1.000 \\
\hline
\end{tabular}

Table-III

Comparison of patients by their clinical features $(N=200)$.

\begin{tabular}{lccc}
\hline Clinical feature & & Group & \\
& Early(n=100) & Delayed (n=100) & -value \\
\hline Duration of cheat pain & $9.5 \pm 5.6$ & $20.5 \pm 14.4$ & $<0.001$ \\
SOB* $^{*}$ & $22(22.0)$ & $37(37.0)$ & 0.020 \\
Sweating* & $58(58.0)$ & $48(48.0)$ & 0.157 \\
Vomiting * & $25(25.0)$ & $15(15.0)$ & 0.202 \\
Syncope ** & $6(6.0)$ & $2(2.0)$ & 0.104 \\
Palpitation * & $11(11.0)$ & $11(11.0)$ & 1.000 \\
Required ventilator ** & $0(0.0)$ & $9(9.0)$ & 0.002 \\
Duration of hospital stay & $3.03 \pm 1.2$ & $3.9 \pm 1.5$ & $<0.001$ \\
Cardiogenic shock * & $4(4.0)$ & $11(11.0)$ & 0.060 \\
ALVF* & $22(22.0)$ & $39(39.0)$ & 0.009 \\
Bronchial asthma COPD* & $6(6.0)$ & $14(14.0)$ & 0.059 \\
Prior MI** & $0(0.0)$ & $4(4.0)$ & 0.061 \\
Prior Stroke ** & $3(3.0)$ & $2(2.0)$ & 0.500 \\
\hline
\end{tabular}

* Chi-square Test was done to analyze the data.

\# Data were analyzed usingUnpaired t-Test and were presented as mean $\pm \mathrm{SD}$.

**Fisher's Exact Test was done to analyze the data.

levels had no significant difference between the two groups.

Figure 2 shows the ECG changes ST elevation was present in $50 \%$ cases in early group, and
$59 \%$ in delayed group. ST depression was present $33 \%$ cases in early group, and $36 \%$ in delayed group. Normal ECG was present $17 \%$ in early group, and $5 \%$ in delayed group. 
Table-IV

Comparison of biochemical findings between groups $(N=200)$.

\begin{tabular}{lccc}
\hline Investigation & \multicolumn{2}{c}{ Group } & p-value \\
\cline { 2 - 3 } & Early $(\mathrm{n}=100)$ & Delayed $(\mathrm{n}=100)$ & \\
\hline Troponin positive* & $83(83.0)$ & $95(95.0)$ & 0.007 \\
CK-MB (U/L) & $33.7 \pm 2.6$ & $31.6 \pm 3.1$ & $<0.001$ \\
Creatinine (mg/dl)\# & $1.1 \pm 0.5$ & $1.2 \pm 0.3$ & 0.358 \\
NT pBNP (pg/ml) & $539.9 \pm 219.8$ & $835.0 \pm 130.6$ & 0.250 \\
SGPT (U/L) & $44.1 \pm 50.9$ & $25.5 \pm 43.9$ & 0.180 \\
\hline
\end{tabular}

* Chi-square Test was done to analyze the data.

\# Data were analyzed usingUnpaired t-Test and were presented as mean $\pm \mathrm{SD}$.

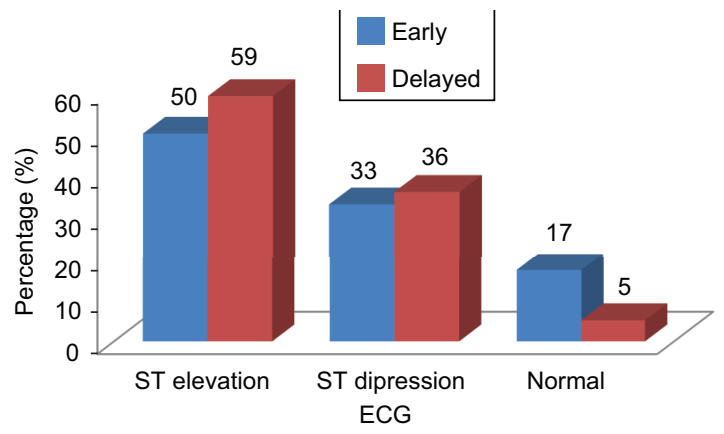

Fig.-2: Comparison of patients by their ECG type.

Table V Coronary angiogram finding revealed that majority of the patient in early invasive group had SVD, whereas delayed invasive group had mostly DVD and TVD. Comparing the two groups it shows that the percentage of DVD were approximately equal in both groups. However the percentage of SVD was more in the early invasive group. Frequency of TVD was higher in delayed group $(p=0.001)$. LAD was the commonest IRA in both the groups $(p=0.114)$.

Table VI shows the treatment characteristics were equally distributed in two groups. All patients were treated with aspirin and Clopidogrel. Ticagrelor used in higher amount in delayed group $(\mathrm{p}=0.052)$ where prasugrel used $56 \%$ in early group and $47 \%$ in delayed group.

Table VII shows that majority of the patient in both groups had mild LV systolic dysfunction, LVEF (45-55) \%. $22 \%$ of patients in the delayed group had moderate LV systolic dysfunction, LVEF (30-44) \% which was 5\% in early invasive group $(\mathrm{p}=0.001)$. Normal LV systolic function LVEF $\geq 55 \%$ constitutes $38.0 \%$ in early group and $20 \%$ in delayed group. $1 \%$ of patients in delayed group had severe LV systolic dysfunction with $\mathrm{EF}<30 \%$.

Table-V

Comparison of Angiographic findings between groups (N=200).

\begin{tabular}{lccc}
\hline Angiographic pattern* & \multicolumn{2}{c}{ Group } & p-value \\
\cline { 2 - 3 } & Early(n=100) & Delayed (n=100) & \\
\hline Vessel involved & $54(54.0)$ & $35(35.0)$ & 0.001 \\
SVD & $40(40.0)$ & $43(43.0)$ & \\
DVD & $6(6.0)$ & $22(22.0)$ & \\
TVD & & & 0.114 \\
IRA (Infarct related artery) & $54(54.0 \%)$ & $40(40.0 \%)$ & 0.027 \\
LAD & $19(19.0 \%)$ & $30(30.0 \%)$ & 0.248 \\
LCX & $27(27.0 \%)$ & $30(30.0 \%)$ & \\
RCA & & & \\
\hline
\end{tabular}

* Chi-square Test was done to analyze the data. 
Table VIII shows Drug eluting stent were commonly used in both groups. The mean no of stents received were $1.3 \pm 0.5$ in early group \& $1.5 \pm 0.7$ in delayed group $(\mathrm{P}=0.062)$. Stent size was same in both the group $2.7 \pm 0.3 \mathrm{~mm}$.

Table IX shows the evaluation of patient at 30 days follow -up after PCI, chest pain and shortness of breath remains higher $(p=<0.001$, $p=0.016)$ in delayed intervention group. LVEF was significantly improved in Early Intervention group $(p=<0.001)$.Left ventricular failure, Reinfarction, stroke, bleeding and AKI, repeat revascularization were higher $(\mathrm{p}=0.004, \mathrm{p}=$ $0.007, p=0.074, p=0.160, p=0.007, p=0.032)$ in delayed intervention group.

Table X shows the adverse outcome was found comparatively higher in delayed invasive group $(\mathrm{p}=0.001), 5 \%$ of patient in delayed invasive group expired which was statistically significant.

\section{Table-VI}

Comparison of use of Medical Therapies between groups ( $N=200)$.

\begin{tabular}{lccc}
\hline Medical therapy* & \multicolumn{2}{c}{ Group } & p-value \\
\cline { 2 - 3 } & Early(n=100) & Delayed $(\mathrm{n}=100)$ & \\
\hline Clopidogrel & $42(42.0)$ & $45(45.0)$ & 0.669 \\
Ticagrelor & $2(2.0)$ & $8(8.0)$ & 0.052 \\
Prasugrel & $56(56.0)$ & $47(47.0)$ & 0.203 \\
Trimetazidine & $66(66.0)$ & $69(69.0)$ & 0.651 \\
BB & $74(74.0)$ & $78(78.0)$ & 0.508 \\
Diuretic & $42(42.0)$ & $50(50.0)$ & 0.256 \\
Nitrate & $80(80.0)$ & $83(83.0)$ & 0.585 \\
Statin & $98(98.0)$ & $92(92.0)$ & 0.052 \\
ACEI_ARB & $49(49.0)$ & $48(48.0)$ & 0.887 \\
CCB & $16(16.0)$ & $15(15.0)$ & 0.845 \\
OHA Insulin & $54(54.0)$ & $57(57.0)$ & 0.669 \\
\hline
\end{tabular}

* Chi-square Test was done to analyze the data.

Table-VII

Comparison of LVEF between groups $(N=200)$

\begin{tabular}{lccc}
\hline EF (\%)* & \multicolumn{2}{c}{ Group } & p-value \\
\cline { 2 - 3 } & Early(n=100) & Delayed (n=100) & \\
\hline Mild & $57(57.0)$ & $57(57.0)$ & 0.001 \\
Moderate & $5(5.0)$ & $22(22.0)$ & \\
Severe dysfunction & $0(0.0)$ & $1(1.0)$ & \\
Normal & $38(38.0)$ & $20(20.0)$ & \\
\hline
\end{tabular}

* Chi-square Test was done to analyze the data.

Table-VIII

Comparison in use of STENT in between groups.

\begin{tabular}{lccc}
\hline Stent information & \multicolumn{2}{c}{ Group } & p-value \\
\cline { 2 - 3 } & Early(n=100) & Delayed $(\mathrm{n}=100)$ & \\
\hline No of Stent \# & $1.3 \pm 0.5$ & $1.5 \pm 0.7$ & 0.062 \\
Stent size(diameter)* & $2.7 \pm 0.3$ & $2.7 \pm 0.3$ & 0.958 \\
Stent type** & & & 0.500 \\
DES & $100(100.0)$ & $99(99.0)$ & \\
BMS & $0(0.0)$ & $1(1.0)$ & \\
\hline
\end{tabular}

* Chi-square Test was done to analyze the data.

\# Data were analyzed usingUnpaired t-Test and were presented as mean $\pm \mathrm{SD}$.

**Fisher's Exact Test was done to analyze the data. 
Table-IX

Comparison of follow-up in between groups $(N=200)$.

\begin{tabular}{lccc}
\hline Follow-up & \multicolumn{2}{c}{ Group } & p-value \\
\cline { 2 - 3 } & Early(n=100) & Delayed (n=100) & \\
\hline Chest pain* & $26(26.0)$ & $52(52.0)$ & $<0.001$ \\
SOB* & $38(38.0)$ & $55(55.0)$ & 0.016 \\
Bleeding* & $11(11.0)$ & $18(18.0)$ & 0.160 \\
ECG change* & & & \\
$\quad$ as before & $99(99.0)$ & $91(91.0)$ & 0.009 \\
$\quad++$ +new changes & $1(1.0)$ & $9(9.0)$ & \\
EF (\%) & $54.7 \pm 7.4$ & $48.4 \pm 6.9$ & $<0.001$ \\
Cardiogenic Shock** & $0(0.0)$ & $3(3.0)$ & 0.123 \\
ALVF* & $7(7.0)$ & $21(21.0)$ & 0.004 \\
AKI* & $5(5.0)$ & $17(17.0)$ & 0.007 \\
Stroke* & $3(3.0)$ & $9(9.0)$ & 0.074 \\
Repeat revascularization** & $1(1.0)$ & $7(7.0)$ & 0.032 \\
Re-infarction* & $0(0.0)$ & $7(7.0)$ & 0.007 \\
\hline
\end{tabular}

* Chi-square Test was done to analyze the data.

\# Data were analyzed usingUnpaired t-Test and were presented as mean $\pm \mathrm{SD}$.

**Fisher's Exact Test was done to analyze the data.

Table-X

Comparison of outcome in between groups $(N=200)$.

\begin{tabular}{|c|c|c|c|}
\hline \multirow[t]{2}{*}{$\overline{\text { Outcome }}$} & \multicolumn{2}{|c|}{ Group } & \multirow[t]{2}{*}{$p$-value } \\
\hline & $\operatorname{Early}(\mathrm{n}=100)$ & Delayed $(n=100)$ & \\
\hline Adverse outcome* & $20(20.0)$ & $45(45.0)$ & $<0.001$ \\
\hline Death** & $0(0.0)$ & $5(5.0)$ & 0.030 \\
\hline
\end{tabular}

* Chi-square Test was done to analyze the data.

**Fisher's Exact Test was done to analyze the data.

\section{Discussion:}

The principal findings of our study are that in patients withACS, an early intervention strategy is superior to a delayed interventionfor the prevention of death, re-infarction and repeat revascularization. Patients who underwent early intervention showed lower rates of death, recurrent ischemia in comparison with those underwent delayed invasive intervention. The principal results of our study are similar to the results of the ISAR-COOL trial that showed a decrease in the rates of death or MI at 30 days in the early intervention group. ${ }^{13}$

Tricoci P, et al. and Swanson N, et al., suggested that earlier intervention as compared with delayed intervention may reduce events. ${ }^{14,15}$ There was no evidence of hazard associated with early intervention at 30 days follow-up. Our findings were matched with their results.
In this present study baseline characteristics of patients show that there was no significant difference regarding the mean age and gender in between groups. Nearly similar pattern of age distribution was reported by Akanda, et al. ${ }^{16}$ in their study in Bangladesh. But there was difference in mean age with different studies done in abroad. ${ }^{17-21}$ Most probably this was due to the late onset of atherosclerotic coronary artery disease in developed countries than that of a third world country population.

Male patients were predominant than female patient in this study. In Bangladesh and abroad various studies showed that the female patients formed a small percentage. ${ }^{14,18,19,21}$

There were similar types of risk factors like obesity, hypertension, diabetes, smoking, dyslipidaemia and family history of IHD in both 
groups. In our study over half of the patients in both groups were overweight or obese. Obese individual have a higher incidence of cardiovascular risk factors such as hypertension, dyslipidemia and diabetes mellitus. Therefore this group of patients had higher morbidity and mortality associated with disease of the cardiovascular system. 39\% patients of early invasive group had normal BMI, where as it was $36 \%$ in case of delayed group. $1 \%$ patient of early invasive group had morbid obesity where there was no patient with morbid obesity in delayed group. Very small percentage of patients was underweight in both groups. Both groups of patient had higher morbidity and mortality associated with disease in the cardiovascular system. The MADIT II study found an inverse correlation between body mass index and total mortality and sudden cardiac death in patient with systolic dysfunction after acute myocardial infarction. ${ }^{17}$

Risk factor distribution showed current smoking and alcohol intake were almost equal in both groups. There was more CKD patient underwent early intervention. Both groups of patient had chest pain, shortness of breath, sweating, vomiting at presentation. Duration of chest pain and shortness of breath were frequently observedin delayed intervention group, whereas sweating, vomiting, and syncope were more frequent in early intervention group. Ventilator requirement was significantly higher, mean duration of hospital stay was longer, cardiogenic shock, acute LVF were significantly higher in delayed group in comparison to early invasive group.

Cardiac Biomarkers Troponin I and CK-MB were significantly raised in delayed group than in the early intervention group. Patients underwent PCI had more frequent cardiac biomarkers elevation. ACCF/AHA guideline, 2014 recommended that high risk patient as older age, Renal dysfunction, Diabetes with elevated cardiac biomarkers are more evident in delayed group. ${ }^{22}$

On admission ST elevation was present in 50\% in early group and $59 \%$ in delayed group. ST depression was found $33 \%$ cases in early group and $36 \%$ in delayed group which is higher compared with previous trials. ${ }^{13,23,24}$
Coronary angiogram findings revealed that that the percentage of DVD were approximately equal in both groups. However the percentage of SVD was more in the early group and TVD in delayed group. LAD artery was most frequently identified as infarct related artery in early group. LCX and RCA was more common IRA in delayed group.Drug Eluting Stent used more in both groups in our study which could prove safer in term of long-term complication.

Treatment characteristics were equally distributed between the groups. Pharmacological treatment regimens were similar in both groups. In the ACUITY trial a greater number of patients undergoing early PCI received aspirin and beta blocker as compared to delayed group which are well known to decrease mortality in patients with ACS. ${ }^{25}$ There was no difference in the medical treatment of post PCI patients between groups. Long term medical compliance was not evaluated.

In ACS patients there was significant left ventricular systolic dysfunction before PCI which was improved in early group after PCI in comparison to delayed group.

At 30-day follow-up, chest pain and SOB was significantly higher in delayed intervention group. New changes of ECG were significant in delayed intervention group. Left ventricular failure, Re-infarction, AKI, stroke, bleeding and death were significantly higher in delayed group. Significant difference was found between the early and delayed intervention group with respect to the composite endpoint of death, reinfarction, ALVF, AKI, bleeding, stroke. Since these events occurred at least 30days after the index hospitalization this difference was irrespective of initial procedure-related myocardial infarction. Repeat revascularization was frequent in delayed intervention group at 30days follow-up compare to early intervention group. TIMACS ${ }^{11}$ reported recurrent ischemia is an important cause for repeat revascularization.

The post-hoc analysis from the two large trials (ACUITY ${ }^{12} \&$ PURSUIT ${ }^{34}$ ) showed improved primary outcome (death or MI) at 30 days in early PCI. OPTIMA ${ }^{24}$ study showed there was no mortality difference between the 2 groups at 
30 days. The improved outcome with early PCI as noted in ISAR-COOL ${ }^{13}$, PURSUIT ${ }^{34}$ \& ACUITY ${ }^{12}$ trial could have been due to rigorous early use of antithrombotic and antiplatelet therapy along with early PCI.

Patient undergoing delayed PCI for management of NSTE-ACS are likely to have higher risk features such as older age, increase biomarkers, and higher burden of co morbidities early intervention may prevent recurrent ischemia and re infarction. Delaying PCI incurs the risk of recurrent ischemia, MI or death likely due to abrupt reoclusion. ${ }^{26}$ In a recent multicenter trial an early d"24hrs invasive strategy in NSTE-ACS patient showed advantage over a delayed invasive strategy ${ }^{11}$ which is consistent in our study. In our study SOB, chest pain, ventilator requirement, ALVF, duration of hospital stay was significantly higher in delayed group.

An early PCI aimed to restore a normal coronary flow may reduce the ischemic time and reduced MI size as a consequence there will be good outcome in early intervention group. Data from the CARESS in AMI study recently reported that high risk patient presenting with evolving STEMI who undergo thrombolytic therapy should be transferred for PCI early after thrombolysis, regardless of the success of thrombolytic therapy. ${ }^{12}$. An additional benefit of early intervention was that it significantly reduce the risk of composite of death, MI. ${ }^{27,28}$

Our finding that earlier intervention is associated with reduced rate of recurrent ischemia and duration of hospital stay appears to be in accord with most of the previous studies and meta-analysis. ${ }^{29-33}$

\section{Conclusion:}

The comparison of clinical findings of patients with early versus delayed invasive intervention groups showed that significantly improvement of chest pain was achieved in patient undergoing early intervention group, whereas shortness of breath, ventilator requirement, duration of hospital stay were significantly predominate in delayed intervention group. Early invasive strategy in ACS patient was associated with lower rates of acute LVF, acute kidney injury, re-infarction, cerebral Stroke, bleeding, repeat revascularization and death compared with delayed invasive strategy at 30 days follow-up. So, early invasive intervention should be the preferred management of Acute Coronary Syndrome than delayed invasive intervention in short term.

\section{Conflict of Interest - None.}

\section{References:}

1. Murray CJL, Lopez AD. Mortality by cause for eight regions of the world. Global Burden of disease study. Lancet 1997; 349(9061): 1269-1276.

2. Sarkees ML, Bavry AA. Acute coronary syndrome (unstable angina and non ST-elevation MI). Clin Evid (online) 2009 (Jan 13); 2009: 0209.

3. Bagai A, Dangas GD, Stone GW, Granger CB. Reperfusion Strategies in Acute Coronary Syndromes. Circulation Research 2014; 114(12):1918-1928.

4. Van de werf F, Bax J, Betriu A, Blomstrom-Lundquist C, Crea F, et al. Management of acute myocardial infarction in patient's presenting with persistent ST-segment elevation: Task Force on the management of ST-segment elevation Acute Myocardial Infarction of the Europian Society of Cardiology. Eur Heart J 2008;28:2909-2945.

5. Windecker S, Kolh P, Alfonso F, Collet JP, Cremer J, Falk V, et al. 2014 ESC/EACTS Guidelines on myocardial revascularization: The Task Force on Myocardial Reavascularization of the European Society of Cardiology (ESC) and Europian Association for Cardio-Thoracic Surgery (EACTS) developed with the special contribution of the European Association of Percutaneous Cardiovascular Intervention(EAPCI). Eur Heart J 2014; 35(37): 2541-2619.

6. Yeh RW, Sidneys S, Chandra M, Sorel M, Selby JV, Go As. Population Trend in the Incidence and Outcomes of Acute Myocardial Infarction. N Engl J Med 2010; 362: 2155-2165.

7. Terkelsen CJ, Lassen JF, Nergard BI, Gerdes JC, Jensent, Gelzsche LB, et al. Mortality rates in patients with ST-elevation vs. Non-ST-elevation acute myocardial infarction: Observation from an unselected Cohort. Eur Heart J 2005; 26: 18-26.

8. Bavry AA, Kumbhani DJ, Rassi AN, Bhatt DL, Askari AT. Benefit of early invasive therapy in acute coronary syndrome: a meta-analysis of contemporary randomized clinical trials. J Am Coll Cardiol 2006; 48: 1319-1325.

9. World Health Organization. World Health Report, 2014. Available online:http://www.who.int/whr/2014/report/en/

10. Roffi M, Patrono C, Collet JP, Mueller C, Valgimigli M, Andreotti F, et al. 2015 ESC Guidelines for the management of acute coronary syndromes in patients presenting without persistent ST-segment elevation: Task Force for the management of Cute Coronary Syndromes in patients presenting without persistent ST-Segment Elevation of the European Society of Cardiology (ESC). Eur Heart J 2015; 37(3): 267-315. 
11. Mehta SR, Grangu CB, Boden WE, Steg PG, Bassand JP, et al. Early versus delayed invasive intervention in acute coronary syndromes. NEng J Med 2009; 360: 2165-2175.

12. Recio Mayoral A, Kaski JC, Mc Murray JJ, Horowitz J, Van Veldhuisan DJ, Remme WJ. Clinical trial update from the European Society of cardiology congress in Vienna, PROSPECT, EVEREST, ARISE, ALOFT, FINESSE, prague-8, CARESS in MI and ACUITY. Cardiovasc Drugs Ther2007; 21:459-465.

13. Neumann FJ, Kastrati A, Pogatsa-Murray G,Mehilli J, Ballwein H, Bestehorn HP, et al. Evaluation of prolonged antithrombotic pretreatment ("Cooling-off" strategy) before intervention in patient with Unstable Coronary Syndrome: a randomized controlled trial. JAMA 2003; 290: 1593-1599.

14. Tricoci P, Lokhnygina Y, Berdan LG,Steinhubl SR, Gulba DC, White HD,et al. Time to coronary angiography and outcomes among patients with high-risk non ST-segment elevation acute coronary syndromes: results from the SYNERGY trial. Circulation 2007; 116: 2669-2677.

15. Swanson N, Montalescot G, Eagle KA, Goodman SG, Huang W, Brieger D,et al. Delay to angiography and outcomes following presentation with high-risk, non-ST-elevation acute coronary syndromes: results from the Global Registry of Acute Coronary Events. Heart 2009; 95: 211-215.

16. Akanda MA, Ali SY, Islam A, Rahman MM, ParveenA, Kabir MK, et al. Demographic profile, Clinical Presentation \& Angiographic Findings in 637patients with Coronary Heart Disease. Faridpur Medical College Journal 2011; 6(2): 82-85.

17. Choi JO, Cho SW, Song YB, Cho SJ, Song BG, Lee SC, et al. Longitudinal $2 \mathrm{D}$ strain at rest predicts the presence of left main and three vessel coronary artery disease in patients without regional wall motion abnormality. Eur $J$ Echocardiogr 2009; 10: 695-701

18. Shimoni S, Gendelman G, Ayzenberg O, Smirin N, Lysyansky P, Edri O, et al. Differential effects of coronary artery stenosis on myocardial function: The value of myocardial strain analysis for the detection of coronary artery disease. J Am Soc Echocardiogr 2011; 24: 748-757.

19. MontgomeryDE, Puthumana JJ, Fox JM,Ogunyankin KO. Global longitudinal strain aids the detection of nonobstructive coronary artery disease in the resting echocardiograme. Eur J Echocardiogr 2011; 282: 1-9.

20. Tsai WC, Liu YW, Huang YY, LinCC, Lee CH, Tsai LM, et al. Diastolic value of segmental longitudinal strain by Automated function imaging in coronary artery disease without left ventricular dysfunction. J Am Soc Echocardiogr 2010; 23: 1183-1189.

21. Sorensen TB, Hoffmann S, Mogelvang R, Iversen AZ, Galatius S, Hansen TF, et al. Myocardial Strain Analysis by 2 -dimentional Speckle Tracking Echocardiography Improves Diagnostic of Coronary Artery Stenosis in Stable Angina Pectoris. Circ Cardiovasc Imaging 2014; 7: 58-65.

22. Amsterdam E, Wenger N, Brindis R, Casey D, Ganiats T, Holmes D, et al. 2014 ACC/AHA Guideline for the management of patients with Non-ST - Elevation Acute Coronary Syndromes: Executive Summary. A Report of the American College of Cardiology/ American Heart Association Task Force on practice Guidelines. J Am Coll Cardiol 2014; 64(24): 39-e228.
23. Thiele H, Rach J, Klein N, Pfeiffer D, Hartmann A, Hambrecht R,et al. LIPSIA-NSTEMI Trial Group. Optimal timing of invasive angiography in stable non-ST-elevation myocardial infarction: the Leipzig immediate versus early and late percutaneous coronary intervention trial in NSTEMI(LIPSIA-NSTEMI trial). Eur Heart J 2012; 33: 2035-2043.

24. Riezebos RK, Ronner E, TerBals E,Slagboom T, Smits PC, Ten Berg JM, et al. Immediate versus deferred coronary angioplasty in non-ST-segment elevation acute coronary syndrome. Heart 2009; 95: 807-812.

25. Chen ZM, Jiang LX, Chen YP, Xie JX, pan HC, Peto R, et al. Addition of clopidogrel to aspirin in 45,852 patients with acute myocardial infarction: randomized placebo-controlled trial. Lancet 2005; 366: 1607-1621.

26. Ohman EM, Califf RM, Topol EJ, Candela R, Abbottsmith $\mathrm{C}$, Ellis S, et al.Consequences of reocclusion after successful reperfusion therapy in acute myocardial infarction:TAMI Study Group. Circulation 1990; 82:781-791.

27. Cannon CP, Braunwald E. Unstable Angina and Non-ST Elevation Myocardial Infarction. In: Bonow RO, Mann DL, Zipes DP, Libby P, eds. Braunwald's Heart Disease: A Textbook of Cardiovascular Medicine. $9^{\text {th }}$ ed. Philadelphia: Elsevier, 2012: 1178-1190.

28. Fox KA, pool-Wilson P, Clayton TC, Henderson RA, Shaw TR, Wheatley DJ, et al. 5-year outcome of an interventional strategy in non-ST-elevation acute coronary syndrome: the British Heart Foundation RITA 3 randomized trial. Lancet 2005; 366: 914-920.

29. Katritsis DG, Siontis GC, KastratiA, VantHof AW, Neumann FJ, Siontis KC, et al. Optimal timing of coronary angiography and potential intervention in non-ST-elevation acute coronary syndromes. Eur Heart J 2011; 32: 32-40.

30. Navarease EP, De Servi S, Gibson CM, Buffon A, Castriota F, Kubika J, et al. Early vs. delayed invasive strategy in patients with acute coronary syndromes without ST-segment elevation: a meta-analysis of randomized studies. QJM2011; 104: 193-200.

31. Rajpurohit N, Garg N, Garg R, Choudhary A, Fresen J, Boren $\mathrm{S}$, et al. Early versus delayed percutaneous coronary intervention for patients with non-ST-segment elevation acute coronary syndrome: a meta analysis of randomized controlled clinical trials. Catheter Cardiovasc Interv 2013; 81: 223-231.

32. Milasinovic D, Milosevic A, MarinkovicJ, Vukcevic V, Ristic A, Asanin M, et al. Timing of invasive strategy in NSTEACS patients and effect on clinical outcomes: a systematic review and meta-analysis of randomized controlled trials. Atherosclerosis 2015; 241: 48-54.

33. Bonello L, Laine M, Puymirat E, Lemesle G, Thuny F, Paqanelli F, et al. Timing of coronary invasive strategy in Non-ST-segment elevation acute coronary syndromes and Clinical outcomes: an update meta-analysis. JACC Cardiovasc Interv 2016; 9: 2267-2276.

34. The PERSUIT Trial Investigators. Inhibition of platelet glycoprotein IIb/IIIa with eptifibatide in patients with acute coronary syndromes without ST-segment elevation. $N$ Engl J Med 1998; 339: 436-443. 